Adriane Batista Pires Maia

(iD) https://orcid.org/0000-0001-6081-707X

Simone Gonçalves Assis

(iD) http://orcid.org/0000-0001-5460-6153

Fernanda Mendes Lages Ribeiro ${ }^{\mathrm{a}}$

(iD) https://orcid.org/0000-0002-3766-9758

a Fundação Oswaldo Cruz (Fiocruz), Escola Nacional de Saúde Pública, Departamento Latino-Americano de Estudos de Violência e Saúde Jorge Careli. Rio de Janeiro, RJ, Brasil.

Contato:

Adriane Batista Pires Maia

E-mail:

adrianepmaia@gmail.com

As autoras declaram que o trabalho não foi subvencionado e que não há conflitos de interesses.

As autoras informam que o trabalho não foi apresentado em eventos científicos e que não é baseado em dissertação ou tese.

\section{Ferimentos por arma de fogo em profissionais de segurança pública e militares das forças armadas: revisão integrativa}

\author{
Firearm injuries to public safety professionals and military \\ personnel: integrative review
}

\section{Resumo}

Objetivo: sistematizar a produção bibliográfica sobre a ocorrência de ferimentos por arma de fogo (FAF) entre profissionais de segurança pública, incluindo policiais e militares de forças armadas. Métodos: revisão integrativa realizada em bases bibliográficas eletrônicas brasileiras e internacionais (BVS, Scopus, Web of Science e Pubmed), sem estipulação de recorte temporal ou territorial. Resultados: foram encontrados 31 artigos segundo os critérios de inclusão e de exclusão. Notou-se aumento crescente de publicações entre 1976 e 2016, a maioria publicada em inglês, em periódicos da área da saúde. Os FAF foram o principal mecanismo de injúria em serviço entre os policiais, mais frequentes entre profissionais do sexo masculino, na faixa etária de 30 anos. As circunstâncias de maior risco foram: ações de prisão e confrontos com criminosos; respostas a chamados policiais para verificação de perturbação à ordem; e em situações de guerra. Existem poucos estudos que discutam as repercussões físicas dos FAF para o exercício profissional dos trabalhadores de segurança pública.

Palavra-chave: segurança pública; policiais; militares; ferimento por arma de fogo; saúde do trabalhador.

\begin{abstract}
Objective: to systematize the bibliographic production on the occurrence of firearm injuries (FAI) among public safety professionals, including police officers and military personnel. Methods: integrative review carried out in Brazilian and international electronic bibliographic databases (Brazilian Virtual Health Library, Scopus, Web of Science and Pubmed), without time or geographic specification. Results: thirty-one articles were found according to the inclusion and exclusion criteria. There was a growing increase of publications between 1976 and 2016, most of them in English and published in health sciences journals. FAI were the mainspring of injury among police officers, most frequent in male professionals, aged range 30. The riskiest circumstances were: arrest actions and clashes with criminals; attendance to police calls to verify order disturbance; and in war situations. There are few studies discussing the physical repercussions of FAI for the public safety workers' professional practice.
\end{abstract}

Keywords: public safety; police officers; military; firearm injury; occupational health. 


\section{Introdução}

Profissionais de segurança pública apresentam maior risco de morte se comparados a outros trabalhadores ${ }^{1-6}$. Nos Estados Unidos da América (EUA), as taxas de acidentes fatais no trabalho são 3 a 4 vezes maiores entre os policiais quando comparadas a profissionais de outros setores e entre os que trabalham no âmbito privado ${ }^{7,8}$. Em virtude da natureza e atribuições da profissão, algumas ocorrências que afetam a saúde são ainda particulares a essa classe de trabalhadores. Hierarquia rígida, exigência de disciplina, relação desgastada do policial com a sociedade - e, por vezes, também conflituosa com o sistema de justiça -, exercício de outras atividades em contraturno, cansaço físico e desgaste emocional ao presenciar colegas sendo mortos na linha de confronto são alguns fatores que têm contribuído para o elevado nível de estresse e de agravos à saúde do policial $^{9-12}$. No Brasil, além desses fatores, elevados níveis de criminalidade, confrontos armados contra grupos do narcotráfico e a grande quantidade de armas de fogo em circulação têm resultado num alto número de policiais atingidos por projétil de arma de fogo, produzindo lesões fatais e/ou incapacitantes e agravando as condições de risco para a saúde ${ }^{13}$.

Segundo Clarke ${ }^{7}$, os profissionais de segurança pública nos EUA reúnem oficiais de polícia, detetives e agentes especiais. Suas atribuições envolvem "a responsabilidade pela garantia da lei, da ordem, da proteção da vida e das propriedades"7 (p. 3). Já Swedler ${ }^{8}$ define os profissionais de segurança pública como aqueles que "trabalham autorizados pela segurança pública oficial, têm plenos poderes de efetuar prisão, normalmente estão previstos no orçamento, carregam arma de fogo e são pagos pelos fundos públicos destinados à segurança pública" (p. 35). As forças armadas americanas estão entre as mais potentes enquanto número de militares e força bélica do mundo e têm desempenhado nas últimas duas décadas uma forte atuação nas guerras do Oriente Médio.

No Brasil, temos uma configuração diferente da norte-americana quanto à organização das forças policiais e suas áreas de atuação. Os profissionais de segurança pública são servidores públicos concursados e têm um regime de trabalho diferente dos profissionais privados, que são regidos pela Consolidação das Leis de Trabalho (CLT). O ingresso na Administração de servidores da segurança pública é feito a partir de concurso conforme exigência do artigo 37 da Constituição ${ }^{14}$.

No âmbito da saúde, os militares das forças armadas seguem modelos da medicina militar, com serviços hospitalares e previdência própria. Já entre os policiais, não há um modelo uniforme de assistência à saúde, existindo variações de acordo com o estado e a categoria policial. Contudo, importa ressaltar que esses servidores possuem regimentos próprios sobre a saúde ocupacional, que diferem dos modelos de saúde ocupacional (como da Organização Internacional do Trabalho - OIT) e da perspectiva da saúde do trabalhador no Sistema Único de Saúde (SUS $)^{1}$. A Constituição da República Federativa do Brasil $^{14}$, nos seus artigos 142 e 144, apresenta as funções, organização e limites constitucionais das instituições públicas responsáveis por exercer a preservação da ordem pública, da incolumidade das pessoas, do patrimônio e da nação. Desse modo, relaciona, entre as instituições que fazem parte dos órgãos de segurança pública no Brasil, as polícias Federal, Rodoviária Federal, Ferroviária Federal, Civil, Militar e o Corpo de Bombeiros. À Polícia Federal cabe apurar as infrações penais de interesses da União ou de suas entidades autárquicas e empresas públicas, de repercussão interestadual ou internacional; à Rodoviária Federal, o patrulhamento ostensivo das rodovias federais; à Civil, as funções de polícia judiciária e a apuração de infrações penais; à Militar, o patrulhamento ostensivo e a preservação da ordem pública; ao Corpo de Bombeiros Militar, além das atribuições definidas na Constituição, está a execução de atividades de defesa civil. A Polícia Militar e o Corpo de Bombeiros Militar são forças auxiliares e de reserva do Exército, de configuração hierarquizada e subordinada, e, juntamente à Polícia Civil, subordinadas aos governadores dos estados. Já as Forças Armadas são instituições nacionais constituídas pela Marinha, Exército e Aeronáutica, sob a autoridade do Presidente da República. Destinam-se à defesa da pátria e dos poderes constitucionais ${ }^{14}$.

Segundo dados do Mapa da Violência ${ }^{15,16}$ sobre homicídios por arma de fogo, entre 1980 e 2014 morreram 967.851 pessoas por disparo de arma de fogo no Brasil, representando 85,8\% do total de homicídios no país. O crescimento da mortalidade por arma de fogo oscilou ao longo desse período: entre 1980 e 2003 cresceu de forma acelerada, numa média de $8,1 \%$ ao ano; a partir de 2003, houve uma redução das mortes por esta causa, o que pode ser explicado, segundo o Mapa ${ }^{15}$, pelo Estatuto e Campanha do Desarmamento, iniciados em 2004; a partir de 2008, o índice novamente oscila e volta a crescer após 2012. O crescimento da letalidade violenta por arma de fogo entre 1980 e 2014 foi de 592,8\% para a população em geral e, quando considerada a faixa etária de 15 a 29 anos, atingiu 699,5\%. O Brasil tem uma taxa de 20,7 homicídios por arma de fogo por 100 mil habitantes, ocupando a $10^{\mathrm{a}}$ posição entre os 100 países analisados pelo Mapa. Nacionalmente, os homens representaram 94,4\% das vítimas de homicídios por armas de fogo ${ }^{15,16}$. 
Dados dos sistemas de vigilância de violência e acidentes ${ }^{17}$, Viva Inquérito (2014) e Viva Contínuo (2013), mostram que, entre os diferentes meios de agressão física, as armas de fogo ocuparam a $4^{\mathrm{a}}$ posição em número de morbidades, com destaque para os homens. Ressalta-se que não é possível conhecer a real magnitude das morbidades produzidas por arma de fogo na população, já que: "no caso de violência extrafamiliar/comunitária, somente são objetos de notificação as violências contra crianças, adolescentes, mulheres, pessoas idosas, pessoa com deficiência, indígenas e população LGBT" (p. 18) ${ }^{17}$; não sendo, portanto, obrigatória a notificação dos casos entre os profissionais de segurança pública ou militares das forças armadas. Tais fatos representam uma grande restrição à compreensão do impacto dos ferimentos por arma de fogo (FAF) nesse grupo da população ${ }^{18}$.

Segundo informações do relatório anual do Fórum de Segurança Pública ${ }^{19}$, em 2016, 358 policiais morreram em virtude da violência em todo país. Em 2019, no primeiro trimestre do ano, 13 policiais militares morreram, somente no estado do Rio de Janeiro, em decorrência da violência ${ }^{20}$. Não há, contudo, um sistema nacional integrado e público que registre a morbimortalidade que envolva todos os profissionais de segurança. Os relatórios sobre a mortalidade ocorrem de maneira fragmentada, por estado, através dos Institutos de Segurança Pública (ISP) ou das Secretarias de Segurança Pública $^{19}$. No Rio de Janeiro, o ISP divulga relatórios mensais sobre as incidências criminais e administrativas envolvendo a segurança do estado, que incluem informações sobre o número de policiais mortos em serviço, mas atualmente não estão especificados os meios que causaram os óbitos. O último relatório de vitimização policial com dados sobre as mortalidades de policiais em serviço por arma de fogo foi publicado em 2015, sem, contudo, trazer informações sobre as morbidades por $\mathrm{FAF}^{21}$. Tampouco os sistemas de informação em saúde do Ministério da Saúde produzem registros sobre as condições de saúde do policial, em virtude da falta de conexão entre os sistemas de informação em saúde dos hospitais militares e os do Ministério da Saúde. Alguns estudos têm buscado avaliar a saúde dos profissionais de segurança pública no país sem, no entanto, produzir uma reflexão mais aprofundada a respeito da representatividade dos efeitos dos FAF na saúde desses profissionais ${ }^{1,11,22-25}$.

O potencial dos traumas por arma de fogo para provocar morbimortalidade, acrescido da escalada da ocorrência desse tipo de ferimento - em razão da entrada de armas com elevado potencial de destruição no país -, torna-se um problema de saúde pública, afetando não apenas a população civil, como também os profissionais de segurança pública ${ }^{6}$. Na traumatologia forense, os FAF são classificados como perfuro-contusos ${ }^{26}$; a forma, extensão e gravidade das lesões dependem da dissipação da energia cinética do projétil na ferida, da capacidade de produção de projéteis secundários e da cavitação que ela produz, podendo resultar no esmagamento, na destruição ou na perfuração das estrutu$\operatorname{ras}^{27,28}$. Tais ferimentos, quando ocorridos em serviço entre os profissionais de segurança pública, tanto para policiais, quanto para militares, constituem-se como acidentes de trabalho $0^{1,5,8,34,35}$.

Este estudo tem como objetivo realizar uma revisão integrativa visando traçar o perfil epidemiológico de profissionais de segurança pública e militares das forças armadas acometidos de FAF, identificar as circunstâncias do trauma e as áreas anatômicas do corpo mais afetadas e conhecer as repercussões na saúde e no desempenho profissional desses sujeitos.

\section{Métodos}

A revisão integrativa ${ }^{29}$ realizada neste artigo visou efetuar análises e sínteses do tema de interesse, possibilitando estabelecer conclusões gerais a seu respeito e apontar lacunas do conhecimento a serem preenchidas com a realização de novos estudos.

A busca bibliográfica foi efetuada no dia 30 de agosto de 2017 nas bases: Portal Regional da Biblioteca Virtual em Saúde (BVS), que incorpora Lilacs, SciELO, Medline e outros tipos de fontes de informação, tais como recursos educacionais abertos, sites de internet e eventos científicos; Scopus; Web of Science e Pubmed. A estratégia de busca utilizada foi: ("polícia" OR "polícia militar") AND ("ferimento por arma de fogo" OR "ferimentos por arma de fogo" OR "projétil por arma de fogo" OR "lesões produzidas por projéteis de arma de fogo" OR "projéteis por arma de fogo"); e em inglês: ("police" OR "military police") AND ("wounds, gunshot" OR "gunshot wounds" OR "firearm injuries” OR "injuries by gunshot” OR "military gunshot wounds"). Não foram estipulados recortes temporal ou territorial. A busca foi realizada por título, resumo e palavras-chave. Buscas manuais foram feitas nas referências bibliográficas dos artigos encontrados.

Para inclusão ou exclusão dos artigos foram empregados os seguintes critérios:

Inclusão: relatos de trauma por arma de fogo em militares das forças armadas ou policiais, relatos sobre morbidade e mortalidade por arma de fogo entre militares das forças armadas e policiais e levantamentos sobre causas de mortalidade e morbidades laborais em policiais e militares das forças armadas;

Exclusão: artigos sobre policiais como autores de agressão por FAF contra civis; textos exclusivamente 
sobre civis vítimas de FAF; testes laboratoriais com armas de fogo e equipamentos de proteção utilizados pelos profissionais; relatos de trauma físico por arma de fogo em grupos de civis e militares das forças armadas e/ou policiais sem distinção dos grupos e sem possibilidade de identificação dos resultados entre os grupos; avaliação exclusiva das repercussões psicológicas em policiais e/ou militares envolvidos em tiroteios; enfoque na avaliação sobre a legislação do uso de arma de fogo; e, ainda, não obtenção de resumo do artigo.

Com base nos critérios adotados, foram identificados 494 estudos. Destes, foram excluídos 165 que apresentavam duplicidade entre as bases. Os 329 títulos e resumos restantes foram lidos, por 2 revisores.
Para os artigos cujos resumos indicavam possibilidade de seleção, era obtida a versão integral, visando confirmar a elegibilidade e a inclusão no estudo. Nos casos em que a leitura do resumo não era suficiente para estabelecer se o estudo deveria ser incluído, o texto também era obtido e lido na íntegra para determinar sua elegibilidade. Foram excluídos 285 artigos. Dos 44 restantes, após aplicação dos critérios de exclusão, 22 foram selecionados. Visando ampliar o escopo da análise, foram realizadas buscas manuais nas referências bibliográficas dos artigos incluídos ${ }^{31}$. Após leitura dos títulos e respectivos resumos e, quando necessário, dos textos na íntegra, incluíram-se mais 9 artigos para a revisão. Dessa forma, 31 documentos compuseram a base analisada neste estudo (Figura 1).

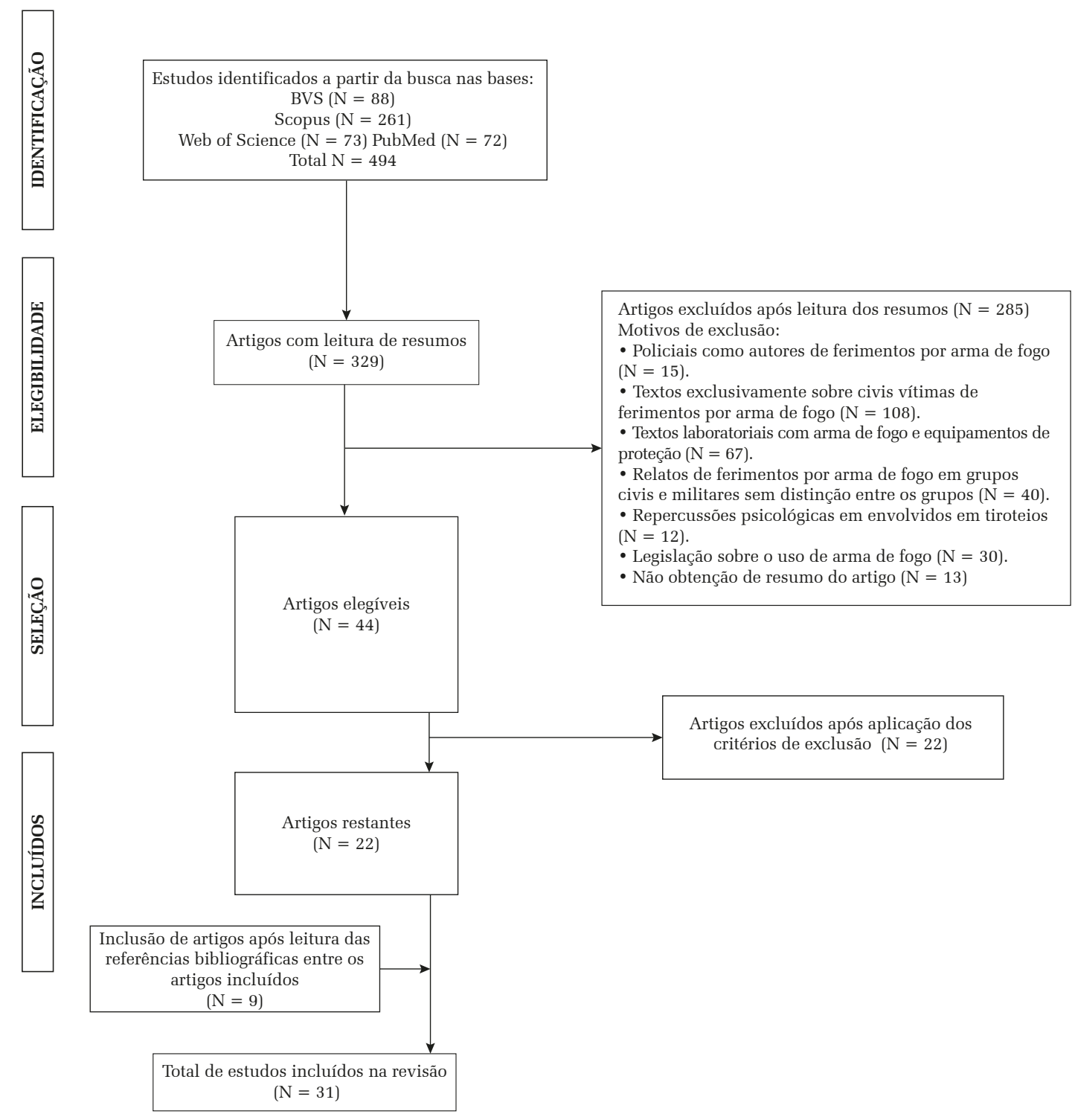

Figura 1 Fluxograma de identificação e seleção dos artigos para revisão sobre a ocorrência de ferimentos por arma de fogo entre profissionais de segurança pública e militares das forças armadas 


\section{Resultados e discussão}

O Quadro 1 permite verificar o(s) país(es) onde ocorreu a violência com FAF, a categoria profissional dos atingidos, o objetivo e os resultados dos artigos selecionados. Tais dados nortearam a descrição e discussão dos resultados do presente artigo.

Entre os 31 textos selecionados, apenas um é nacional ${ }^{47}$, apresentando o relato de caso de um policial brasileiro vítima de arma de fogo. Não foram encontrados levantamentos sobre as condições de saúde dos profissionais de segurança brasileiros frente aos FAF, o que indica a precariedade da informação e de estudos sobre o tema no país.

Dos artigos analisados, 21 documentos referem-se a ocorrências relacionadas a profissionais de segurança pública (policiais) e 10 a militares das forças armadas. Dentre estes últimos, 9 descreveram situações de guerra ${ }^{32-37,39-41}$, dos quais 6 incluíram civis e militares discriminadamente no mesmo estudo $^{9,33,34,38,39,43,} 2$ envolveram levantamentos entre militares das forças armadas mortos e feridos em guerras ocorridas no século $\mathrm{XX}^{33,34}$ e 7 em conflitos mais recentes, ocorridos entre 2003 e 2009 no Oriente Médio, especialmente no Afeganistão, Iraque e Kuwait ${ }^{32,35-37,39-41}$. Esses estudos foram realizados a partir da análise dos atendimentos a militares de países que formaram a coalizão internacional contra o terrorismo, especialmente EUA, Reino Unido e Espanha.
Ainda conforme o Quadro 1, observou-se que os EUA se destacaram como o local com maior número de publicações, totalizando 12 artigos, todos com algum tipo de informação referente a profissionais de segurança pública, em especial aos oficiais de polícia, mortos ou feridos por arma de fogo. Deve-se levar em conta que o maior número de publicações não significa, necessariamente, que esse país tenha um maior número de policiais vitimados por armas de fogo, e sim que há uma melhor qualidade de registros de casos e, possivelmente, bancos de dados e relatórios publicados com periodicidade e transparência, permitindo a realização de estudos.

Encontraram-se nos artigos três diferentes fontes de dados: o Labor's Census of Fatal Occupational Injuries, que apresenta um censo sobre a ocorrência de mortes e ferimentos ocupacionais a partir de dados das principais profissões, incluindo os profissionais de segurança do país; o Annual Law Enforcement Officers Killed and Assaulted (Leoka), um relatório anual publicado pelo Federal Bureau of Investigation (FBI) desde 1996 que realiza o levantamento das ocorrências de mortes e ferimentos entre os profissionais de segurança; e o National Violent Death Report System (NVDRS), sistema de notificação de mortes violentas dos EUA, que, diferentemente dos brasileiros, disponibiliza os dados de mortalidade de profissionais de segurança pública em todo país a partir da integração do banco de dados do Leoka, das informações obtidas nos prontuários dos médicos legistas e dos registros nos boletins de ocorrência policiais.

Quadro 1 Artigos identificados na revisão, segundo autor, ano de publicação, país onde ocorreram os ferimentos por armas de fogo (FAF), categoria profissional dos feridos, objetivo, metodologia e resultados do artigo

\begin{tabular}{|l|l|l|l|l|}
\hline $\begin{array}{c}\text { Autor, ano } \\
\text { e país }\end{array}$ & $\begin{array}{l}\text { Categoria } \\
\text { profissional }\end{array}$ & \multicolumn{1}{|c|}{ Objetivo } & \multicolumn{1}{c|}{ Métodos } & \multicolumn{1}{c|}{ Resultados } \\
\hline $\begin{array}{l}\text { Wilson }{ }^{51}, \\
\text { 1976. EUA }\end{array}$ & Policiais & $\begin{array}{l}\text { Relatar caso de policial vítima de } \\
\text { FAF envolvendo o cólon e medula, } \\
\text { com perfuração da veia cava. }\end{array}$ & $\begin{array}{l}\text { Relato de caso clínico. } \\
\text { infecciosa tardia e veio a óbito } \\
\text { em decorrência de meningite. } \\
\text { Sugeriu-se o uso de antibiótico e } \\
\text { monitoramento através de punção } \\
\text { lombar diária para esse tipo de } \\
\text { ferimento. }\end{array}$ \\
\hline $\begin{array}{l}\text { Lester }{ }^{54}, \\
1982 . \text { EUA }\end{array}$ & Policiais & $\begin{array}{l}\text { Explorar a relação entre as } \\
\text { características das armas de mão } \\
\text { confiscadas nas cidades com } \\
\text { projeto de identificação de armas } \\
\text { e os assassinatos de policiais. }\end{array}$ & $\begin{array}{l}\text { Estudo quantitativo de base } \\
\text { ecológica que analisa taxas } \\
\text { de mortalidade policial e } \\
\text { apreensão de armas de fogo } \\
\text { no período de 1970 a 1975. }\end{array}$ & $\begin{array}{l}\text { Depreende-se do estudo que as } \\
\text { mortes de policiais ocorrem com } \\
\text { maior frequência em cidades onde } \\
\text { os criminosos se utilizam mais } \\
\text { de armas menos caras, como os } \\
\text { revólveres de cano curto. }\end{array}$ \\
\hline $\begin{array}{l}\text { Raghib }{ }^{53}, \\
1984 . \\
\text { Jordânia }\end{array}$ & $\begin{array}{l}\text { Militares } \\
\text { de forças } \\
\text { armadas, } \\
\text { policiais, } \\
\text { civis }\end{array}$ & $\begin{array}{l}\text { Avaliar a causa das mortes por } \\
\text { arma de fogo em Amam. }\end{array}$ & $\begin{array}{l}\text { Estudo quantitativo a partir } \\
\text { de prontuários das autópsias } \\
\text { realizadas no Departamento } \\
\text { de Medicina Forense no } \\
\text { período de 8 anos (N = 221). }\end{array}$ & $\begin{array}{l}\text { Entre todos os casos de óbitos } \\
\text { por FAF, 20,3\% foram de militares } \\
\text { das forças armadas e policiais, } \\
\text { equivalendo a 14\% dos homicídios, } \\
\text { 25\% dos acidentes e 30\% dos } \\
\text { suicídios. }\end{array}$ \\
\hline
\end{tabular}


Quadro 1 Continuação...

\begin{tabular}{|c|c|c|c|c|}
\hline $\begin{array}{c}\text { Autor, ano } \\
\text { e país }\end{array}$ & $\begin{array}{l}\text { Categoria } \\
\text { profissional }\end{array}$ & Objetivo & Métodos & Resultados \\
\hline $\begin{array}{l}\text { Berman e } \\
\text { Salter }{ }^{48} \text {, } \\
\text { 1985. EUA }\end{array}$ & Policiais & $\begin{array}{l}\text { Identificar as circunstâncias } \\
\text { que culminaram em FAF entre } \\
\text { policiais da Filadélfia. Analisar } \\
\text { a localização do ferimento, o } \\
\text { tempo de hospitalização e de } \\
\text { afastamento de serviço e as } \\
\text { repercussões psicológicas do } \\
\text { trauma sofrido. }\end{array}$ & $\begin{array}{l}\text { Estudo quantitativo a } \\
\text { partir de prontuários da } \\
\text { polícia da Filadélfia, de } \\
\text { policiais acometidos por } \\
\text { FAF no período de } 12 \text { anos } \\
(\mathrm{N}=145) \text {. }\end{array}$ & $\begin{array}{l}\text { Foram } 188 \text { FAF, com } 20 \text { fatalidades. } \\
\text { Prisão e tentativa de prisão são } \\
\text { circunstâncias comuns envolvidas } \\
\text { nas causas das ocorrências. Grande } \\
\text { parte dos ferimentos poderia ter sido } \\
\text { evitada com uso dos equipamentos } \\
\text { de proteção. Média de internação } \\
\text { de } 10 \text { dias. Tempo de afastamento } \\
\text { de serviço de } 143 \text { dias em média. } \\
\text { Sequelas permanentes e deficiências } \\
\text { parciais em virtude das feridas em } \\
22 \text { policiais. Ansiedade no retorno } \\
\text { ao serviço em } 12 \text { policiais. Reforma } \\
\text { (aposentadoria) por instabilidade } \\
\text { emocional em } 2 \text { casos. }\end{array}$ \\
\hline $\begin{array}{l}\text { Lester }^{55} \\
\text { 1987. EUA }\end{array}$ & Policiais & $\begin{array}{l}\text { Investigar a relação entre o uso } \\
\text { de arma de fogo em roubos e } \\
\text { assaltos e a taxa de mortes de } \\
\text { policiais em } 37 \text { cidades grandes } \\
\text { nos EUA. }\end{array}$ & $\begin{array}{l}\text { Estudo quantitativo de base } \\
\text { ecológica que analisa taxas } \\
\text { de mortalidade policial e } \\
\text { assaltos e roubos com o uso } \\
\text { de arma de fogo, no período } \\
\text { de } 1970 \text { a } 1978 .\end{array}$ & $\begin{array}{l}\text { Maiores taxas de policiais } \\
\text { assassinados em cidades com maior } \\
\text { proporção de suicídios, homicídios, } \\
\text { roubos e assaltos envolvendo arma de } \\
\text { fogo. Maior acesso a armas de fogo } \\
\text { por criminosos é causa provável de } \\
\text { violência contra o policial. }\end{array}$ \\
\hline $\begin{array}{l}\text { Ebbs }^{42} \text {, } \\
\text { 1990. Reino } \\
\text { Unido }\end{array}$ & Policiais & $\begin{array}{l}\text { Relatar o caso de policial de } 29 \\
\text { anos que se feriu acidentalmente } \\
\text { durante treinamento com arma } \\
\text { de fogo. }\end{array}$ & Relato de caso clínico. & $\begin{array}{l}\text { O projetil foi removido sob anestesia } \\
\text { local sem intercorrências. }\end{array}$ \\
\hline $\begin{array}{l}\text { Armour }^{9} \text {, } \\
\text { 1996. Reino } \\
\text { Unido }\end{array}$ & $\begin{array}{l}\text { Policiais, } \\
\text { Civis }\end{array}$ & $\begin{array}{l}\text { Analisou os fatores associados } \\
\text { ao suicídio por arma de fogo } \\
\text { ocorridas no Reino Unido. }\end{array}$ & $\begin{array}{l}\text { Estudo quantitativo com } \\
\text { dados do inquérito nacional } \\
\text { do Reino Unido sobre os } \\
\text { casos de suicídio em período } \\
\text { de } 5 \text { anos }(\mathrm{N}=104) \text {. }\end{array}$ & $\begin{array}{l}\text { Ocorrência de } 104 \text { casos de suicídio } \\
\text { por FAF ( } 45 \text { entre policiais). Estresse } \\
\text { psicológico e facilidade de acesso } \\
\text { a armas de fogo foram fatores } \\
\text { associados às ocorrências de } \\
\text { suicídios entre policiais e civis. }\end{array}$ \\
\hline $\begin{array}{l}\text { Gofrit } \\
\text { et al. }{ }^{32} \text {, } \\
\text { 1996. Líbano }\end{array}$ & $\begin{array}{l}\text { Militares } \\
\text { de Forças } \\
\text { Armadas }\end{array}$ & $\begin{array}{l}\text { Identificar a localização } \\
\text { anatômica dos FAF entre soldados } \\
\text { mortos na guerra, no período em } \\
\text { que ocorreram } 65 \% \text { de todas as } \\
\text { mortes da guerra. }\end{array}$ & $\begin{array}{l}\text { Estudo quantitativo } \\
\text { descritivo a partir de } \\
\text { dados de prontuários de } \\
\text { militares mortos em } 3 \text { meses } \\
\text { de combate no Líbano } \\
(\mathrm{N}=229) .\end{array}$ & $\begin{array}{l}\text { Ocorreram } 405 \text { ferimentos, } 115 \\
\text { destes por FAF }(28,4 \%) \text {. Face é a área } \\
\text { com a maior densidade de ferimentos } \\
\text { penetrantes, representando } 7,3 \\
\text { vezes mais do que a proporção de } \\
\text { toda superfície do corpo. Achados } \\
\text { sugerem a necessidade da criação } \\
\text { de dispositivo adicional de proteção } \\
\text { para a face. }\end{array}$ \\
\hline $\begin{array}{l}\text { Clarke e } \\
\text { Zak }^{7}, 1999 . \\
\text { EUA }\end{array}$ & Policiais & $\begin{array}{l}\text { Analisar as circunstâncias } \\
\text { envolvidas nas fatalidades } \\
\text { ocupacionais entre profissionais } \\
\text { de segurança. }\end{array}$ & $\begin{array}{l}\text { Estudo quantitativo } \\
\text { descritivo com dados do U.S. } \\
\text { Bureau of Labor Statistic's- } \\
\text { Census of Fatal Occupational } \\
\text { Injuries no período de } 1992 \text { a } \\
1997(\mathrm{~N}=887) \text {. }\end{array}$ & $\begin{array}{l}\text { Taxa de mortalidade ocupacional } \\
\text { é } 3 \text { vezes maior se comparada a } \\
\text { outras profissões, apontando para o } \\
\text { alto risco ocupacional envolvido na } \\
\text { profissão. Maior parte das fatalidades } \\
\text { decorre de homicídios ( } 9 \text { em cada } \\
10 \text { homicídios por FAF) e ocorre em } \\
\text { áreas urbanas. }\end{array}$ \\
\hline $\begin{array}{l}\text { Rupp et al. }{ }^{47}, \\
2001 . \\
\text { Alemanha }\end{array}$ & Policiais & $\begin{array}{l}\text { Relatar caso de policial de } 41 \text { anos } \\
\text { de idade que cometeu suicídio } \\
\text { por disparo com arma de fogo } \\
\text { na região temporal esquerda e } \\
\text { sofreu lacerações na face por } \\
\text { mordida canina pós morte. }\end{array}$ & Relato de caso clínico. & $\begin{array}{l}\text { O corpo foi encontrado } 12 \text { horas mais } \\
\text { tarde, com danos por mordida canina } \\
\text { ao redor do FAF no rosto. Apesar } \\
\text { disso, os ferimentos correspondentes } \\
\text { aos orifícios de entrada e saída do } \\
\text { projétil por arma de fogo não foram } \\
\text { afetados pela dilaceração proveniente } \\
\text { das mordidas caninas. }\end{array}$ \\
\hline
\end{tabular}

(Continua) 
Quadro 1 Continuação...

\begin{tabular}{|c|c|c|c|c|}
\hline $\begin{array}{c}\text { Autor, ano } \\
\text { e país }\end{array}$ & $\begin{array}{l}\text { Categoria } \\
\text { profissional }\end{array}$ & Objetivo & Métodos & Resultados \\
\hline $\begin{array}{l}\text { Champion } \\
\text { et al. }{ }^{31} \text {, } \\
\text { 2003. Vários }\end{array}$ & $\begin{array}{l}\text { Militares } \\
\text { de Forças } \\
\text { Armadas }\end{array}$ & $\begin{array}{l}\text { Analisar a natureza das lesões } \\
\text { traumáticas de combate em guerras } \\
\text { registrados no Wound Data and } \\
\text { Munition Effectiveness Team. } \\
\end{array}$ & $\begin{array}{l}\text { Estudo epidemiológico } \\
\text { do período de 1967-69. } \\
\text { ( } \mathrm{N}=7989) \text {, a partir do } \\
\text { banco de dados Wound Data } \\
\text { and Munition Effectiveness } \\
\text { Team, que soma dados de } \\
\text { várias guerras em diferentes } \\
\text { períodos e países. }\end{array}$ & $\begin{array}{l}\text { Os FAF representaram } 23 \% \text { dos } \\
\text { ferimentos de guerra, sendo mais } \\
\text { encontrados entre os militares da } \\
\text { infantaria. A cada } 3 \text { militares vítimas } \\
\text { de arma de fogo, } 1 \text { morre; a cada } 20 \\
\text { militares atingidos por fragmentos } \\
\text { explosivos, } 1 \text { é morto. }\end{array}$ \\
\hline $\begin{array}{l}\text { Plani, } \\
\text { Bowley e } \\
\text { Goosen }{ }^{46} \\
\text { 2003. África } \\
\text { do Sul }\end{array}$ & Policiais & $\begin{array}{l}\text { Obter informações nos } \\
\text { prontuários de policiais } \\
\text { atendidos, em virtude de FAF } \\
\text { sofridos em serviço. Identificar } \\
\text { o tipo de ferimento, os aspectos } \\
\text { demográficos, locais anatômicos } \\
\text { acometidos, forma de transporte } \\
\text { ao hospital, utilização de } \\
\text { equipamento de proteção } \\
\text { individual e se este foi efetivo, } \\
\text { mortalidade e tempo de retorno } \\
\text { ao trabalho. }\end{array}$ & $\begin{array}{l}\text { Estudo quantitativo com } \\
\text { levantamento de dados } \\
\text { secundários de prontuários } \\
\text { dos policiais atendidos em } \\
\text { virtude de ferimentos em } \\
\text { serviço, no período de junho } \\
\text { de } 1993 \text { a junho de } 2002 \text { no } \\
\text { Hospital de Milpark. }(\mathrm{N}=134)\end{array}$ & $\begin{array}{l}\text { 95\% dos policiais eram do sexo } \\
\text { masculino, com idade média de } 31 \\
\text { anos. Entre os } 92 \text { policiais atendidos } \\
\text { feridos por arma de fogo, } 80 \text { casos } \\
\text { aconteceram durante o serviço; houve } \\
3 \text { suicídios e } 9 \text { disparos acidentais. } 55 \% \\
\text { dos policiais feridos eram sargentos; } \\
35 \% \text { utilizavam colete à prova de bala. } \\
\text { Sobre o retorno ao trabalho: } 58 \% \\
\text { policiais foram considerados aptos, } 21 \% \\
\text { parcialmente aptos (para serviços leves) } \\
\text { e } 21 \% \text { afastados. Os meios de socorro } \\
\text { utilizados foram: ambulância (76), } \\
\text { helicópteros médicos (39) e policiais (5), } \\
\text { carros de polícia (13) e carro privado (1). }\end{array}$ \\
\hline $\begin{array}{l}\text { Gutiérrez } \\
\text { e Radice }{ }^{44} \\
\text { 2003. Chile }\end{array}$ & Policiais & $\begin{array}{l}\text { Relatar caso de policial que, } \\
\text { tendo sido atingido por projétil } \\
\text { de arma de fogo, } 54 \text { meses após o } \\
\text { evento sofreu migração do projétil } \\
\text { para a região intra-articular, } \\
\text { com consequente limitação de } \\
\text { amplitude de movimento articular. } \\
\end{array}$ & Relato de caso clínico. & $\begin{array}{l}\text { O projétil foi removido através } \\
\text { de cirurgia artroscópica. Não } \\
\text { houve lesão dentro da articulação } \\
\text { relacionada ao corpo solto. }\end{array}$ \\
\hline $\begin{array}{l}\text { Ehikhamenor } \\
\text { e Ojo }{ }^{43} \text {, } \\
\text { 2005. Nigéria }\end{array}$ & $\begin{array}{l}\text { Policiais, } \\
\text { civis }\end{array}$ & $\begin{array}{l}\text { Realizar análise comparativa da } \\
\text { frequência de mortes causadas } \\
\text { por assaltos com uso de armas } \\
\text { de fogo e as mortes em acidentes } \\
\text { rodoviários. }\end{array}$ & $\begin{array}{l}\text { Estudo quantitativo a partir } \\
\text { de levantamento de banco de } \\
\text { dados institucionais da polícia } \\
\text { da Nigéria num período de } 5 \\
\text { meses }(\mathrm{N}=511) . \\
\end{array}$ & $\begin{array}{l}\text { Entre as pessoas mortas em assalto } \\
\text { a mão armada estavam: transeuntes } \\
(26 \%) \text {, assaltantes (68\%) e policiais } \\
(5,7 \%) \text {, estes do sexo masculino, na } \\
\text { faixa de } 21 \text { a } 32 \text { anos. }\end{array}$ \\
\hline $\begin{array}{l}\text { Hinsley } \\
\text { et al. } .^{33} \text {, } \\
2005 . \\
\text { Kuwait }\end{array}$ & $\begin{array}{l}\text { Militares } \\
\text { de forças } \\
\text { armadas, } \\
\text { civis }\end{array}$ & $\begin{array}{l}\text { Apresentar relato de experiência } \\
\text { do hospital britânico de } \\
\text { campanha durante a fase mais } \\
\text { intensa do conflito do Golfo. }\end{array}$ & $\begin{array}{l}\text { Estudo quantitativo com } \\
\text { dados de prontuários de } \\
\text { pacientes atendidos em } 202 \\
\text { hospitais de campanha no } \\
\text { período de } 21 \text { de março a } 4 \\
\text { de abril de } 2003 \text { na guerra do } \\
\text { Kuwait }(\mathrm{N}=482) \text {. } \\
\end{array}$ & $\begin{array}{l}\text { Entre os pacientes atendidos, } 79 \\
\text { apresentavam lesões penetrantes por } \\
\text { arma de fogo; entre esses, } 33 \text { eram } \\
\text { militares. }\end{array}$ \\
\hline $\begin{array}{l}\text { Niosh }^{52} \text {, } \\
\text { 2006. EUA }\end{array}$ & Policiais & $\begin{array}{l}\text { Relatar caso de tenente de } \\
\text { carreira do sexo feminino, morta } \\
\text { por FAF ao fornecer atendimento } \\
\text { de emergência a civil baleado. }\end{array}$ & Relato de caso clínico. & $\begin{array}{l}\text { A vítima e um colega bombeiro } \\
\text { paramédico estavam realizando } \\
\text { uma avaliação inicial do paciente } \\
\text { quando foram alvejados. Apesar das } \\
\text { tentativas de ressuscitação, a policial } \\
\text { foi a óbito. }\end{array}$ \\
\hline $\begin{array}{l}\text { Kyriacou } \\
\text { et al. }{ }^{49} \text {, } \\
\text { 2006. EUA e } \\
\text { Reino Unido }\end{array}$ & Policiais & $\begin{array}{l}\text { Descrever a incidência e as causas } \\
\text { das mortes entre os policiais das } \\
\text { cidades de Nova lorque e Londres } \\
\text { durante o século XX. Analisar se } \\
\text { existe relação entre as taxas de } \\
\text { homicídios de civis e de policiais. }\end{array}$ & $\begin{array}{l}\text { Estudo quantitativo de } \\
\text { base ecológica para análise } \\
\text { das tendências de mortes } \\
\text { ocupacionais entre policiais } \\
\text { em um período de } 100 \text { anos } \\
(\mathrm{N}=322) \text {. }\end{array}$ & $\begin{array}{l}\text { Os FAF representaram a principal } \\
\text { causa de morte entre os policiais de } \\
\text { Nova lorque, com } 302 \text { mortes listadas } \\
\text { durante o século XX. Já em Londres, } \\
\text { foram encontrados } 20 \text { casos de morte } \\
\text { de policiais em decorrência de FAF. } \\
\text { Não foi encontrada correlação entre } \\
\text { as taxas de homicídios de civis e } \\
\text { policiais em ambas as cidades. }\end{array}$ \\
\hline
\end{tabular}

(Continua) 
Quadro 1 Continuação...

\begin{tabular}{|c|c|c|c|c|}
\hline $\begin{array}{l}\text { Autor, ano } \\
\text { e país }\end{array}$ & $\begin{array}{c}\text { Categoria } \\
\text { profissional }\end{array}$ & Objetivo & Métodos & Resultados \\
\hline $\begin{array}{l}\text { Bird e } \\
\text { Fairweather }^{30} \text {, } \\
\text { 2007. Iraque } \\
\text { e Afeganistão }\end{array}$ & $\begin{array}{l}\text { Militares } \\
\text { de forças } \\
\text { armadas }\end{array}$ & $\begin{array}{l}\text { Identificar as principais causas } \\
\text { de morte dos militares nas duas } \\
\text { guerras. }\end{array}$ & $\begin{array}{l}\text { Estudo quantitativo } \\
\text { multicêntrico realizado a } \\
\text { partir do banco de dados } \\
\text { iCasualties.org para análise } \\
\text { das mortes ocasionadas pelo } \\
\text { combate e por doenças ou } \\
\text { acidentes. Período analisado } \\
\text { de } 260 \text { dias }(\mathrm{N}=537) \text {. }\end{array}$ & $\begin{array}{l}\text { Entre as mortes de militares, } 90 \\
\text { ocorreram em virtude de lesões por } \\
\text { arma de fogo. As mortes por arma de } \\
\text { fogo corresponderam a } 13 \% \text { do total } \\
\text { no Iraque e } 12 \% \text { no Afeganistão. }\end{array}$ \\
\hline $\begin{array}{l}\text { Wade } \\
\text { et al. }{ }^{37} \text {, } \\
\text { 2007. Iraque }\end{array}$ & $\begin{array}{l}\text { Militares } \\
\text { de forças } \\
\text { armadas }\end{array}$ & $\begin{array}{l}\text { Documentar as características e } \\
\text { causas dos ferimentos na cabeça, } \\
\text { pescoço e face durante operação } \\
\text { militar. }\end{array}$ & $\begin{array}{l}\text { Estudo epidemiológico } \\
\text { descritivo a partir de } \\
\text { dados institucionais das } \\
\text { Forças Militares, Marinha e } \\
\text { Aeronáutica sobre militares } \\
\text { feridos no período de } 1 \text { de } \\
\text { março a } 30 \text { de setembro de } \\
2004 \text { em operação no Iraque } \\
(\mathrm{N}=445) \text {. }\end{array}$ & $\begin{array}{l}1 / 3 \text { dos militares vitimados } \\
\text { apresentaram feridas múltiplas nas } \\
3 \text { áreas. Dispositivos explosivos } \\
\text { improvisados foram a causa mais } \\
\text { frequente dos ferimentos. Lesões } \\
\text { na cabeça, em geral, foram mais } \\
\text { severas do que as feridas na face ou } \\
\text { no pescoço. Recomenda-se melhor } \\
\text { proteção para a face. Idade média de } \\
24 \text { anos (DP = 5,9 anos). } \\
\end{array}$ \\
\hline $\begin{array}{l}\text { Hodgetts } \\
\text { et al. } .^{34} \\
2007 . \\
\text { Afeganistão }\end{array}$ & $\begin{array}{l}\text { Militares } \\
\text { de forças } \\
\text { armadas, } \\
\text { civis }\end{array}$ & $\begin{array}{l}\text { Avaliar a causas das mortes } \\
\text { no primeiro ano de operações } \\
\text { militares. Comparar os } \\
\text { mecanismos causadores de } \\
\text { ferimento por ação hostil e não } \\
\text { hostil. }\end{array}$ & $\begin{array}{l}\text { Estudo quantitativo a partir } \\
\text { de banco de dados da } \\
\text { agência Defence Analytical } \\
\text { Services and Advice no } \\
\text { período de } 1 \text { de abril de } \\
2006 \text { a } 31 \text { de março de } 2007 \\
(\mathrm{~N}=76) \text {. }\end{array}$ & $\begin{array}{l}\text { O mapeamento corporal de } \\
\text { lesões balísticas mostrou maior } \\
\text { vulnerabilidade da face e pescoço. } \\
\text { Cabeça e tórax representaram a } \\
\text { maioria das lesões letais. }\end{array}$ \\
\hline $\begin{array}{l}\text { Kelly et al. }{ }^{35} \text {, } \\
2008 . \\
\text { Iraque e } \\
\text { Afeganistão }\end{array}$ & $\begin{array}{l}\text { Militares } \\
\text { de forças } \\
\text { armadas }\end{array}$ & $\begin{array}{l}\text { Avaliar se houve agravamento } \\
\text { e aumento dos ferimentos nas } \\
\text { Guerras do Iraque e Afeganistão e } \\
\text { identificar a causa de morte entre } \\
\text { os militares. }\end{array}$ & $\begin{array}{l}\text { Estudo epidemiológico a } \\
\text { partir de levantamento de } \\
\text { dados institucionais das } \\
\text { Forças Armadas dos EUA } \\
\text { (Defense Manpower Data } \\
\text { Center, Statistical Information } \\
\text { Analysis Division) no período } \\
\text { de março de } 2003 \text { a abril } \\
\text { de } 2004 \text { e junho de } 2006 \\
\text { a dezembro de } 2006 \\
(\mathrm{~N}=982) \text {. }\end{array}$ & $\begin{array}{l}\text { Aumento de mortes se comparadas } \\
\text { a outras guerras. Hemorragia é a } \\
\text { principal causa potencial de mortes. } \\
486 \text { militares mortos no Iraque ( } 30 \% \\
\text { por FAF), } 496 \text { militares mortos no } \\
\text { Afeganistão ( } 24 \% \text { por FAF). }\end{array}$ \\
\hline $\begin{array}{l}\text { Clerici } \\
\text { et al. }{ }^{41} \text {, } \\
\text { 2009. Itália }\end{array}$ & Policiais & $\begin{array}{l}\text { Avaliar as taxas de homicídio } \\
\text { e suicídio entre os policiais, } \\
\text { comparados a outras populações } \\
\text { (1996-2006). Entender as } \\
\text { circunstâncias do trauma e } \\
\text { conhecer a idade média das } \\
\text { vítimas. }\end{array}$ & $\begin{array}{l}\text { Estudo quantitativo de base } \\
\text { empírica a partir de consulta } \\
\text { sistemática de fontes } \\
\text { jornalísticas de informação, } \\
\text { referentes a um período de } \\
10 \text { anos, de } 1^{\circ} \text { de janeiro de } \\
1996 \text { a } 31 \text { de dezembro de } \\
2006(N=50) \text {. }\end{array}$ & $\begin{array}{l}50 \text { casos de suicídios entre os } \\
\text { policiais ( } 45 \text { com arma de fogo e } 5 \\
\text { por outros meios), com idade média } \\
\text { de } 37,4 \text { anos, sendo } 49 \text { do sexo } \\
\text { masculino e } 1 \text { do sexo feminino. } \\
\text { Transtornos psiquiátricos, doenças } \\
\text { físicas e razões econômicas foram as } \\
\text { causas associadas. Foram } 44 \text { casos } \\
\text { de homicídios com arma de fogo } \\
\text { contra policiais. Incidência elevada de } \\
\text { suicídios e homicídios entre policiais } \\
\text { comparada ao restante da população. }\end{array}$ \\
\hline $\begin{array}{l}\text { Stansfield e } \\
\text { Rushforth }{ }^{36} \text {, } \\
\text { 2009. Reino } \\
\text { Unido }\end{array}$ & $\begin{array}{l}\text { Militares } \\
\text { de forças } \\
\text { armadas }\end{array}$ & $\begin{array}{l}\text { Informar a incidência de FAF por } \\
\text { disparos acidentais. }\end{array}$ & $\begin{array}{l}\text { Estudo quantitativo a partir de } \\
\text { banco de dados institucionais } \\
\text { das forças armadas do } \\
\text { Reino Unido denominado } \\
\text { Munition Incidents and Defects, } \\
\text { no período de } 3 \text { de janeiro } \\
\text { a } 31 \text { de dezembro de } 2007 \\
(\mathrm{~N}=1.158) \text {. }\end{array}$ & $\begin{array}{l}\text { Ocorreram } 1.158 \text { disparos não } \\
\text { intencionais por armas de fogo; } 4 \% \\
\text { destes resultaram em } 55 \text { ferimentos, } \\
\text { incluindo uma fatalidade. }\end{array}$ \\
\hline
\end{tabular}

(Continua) 
Quadro 1 Continuação...

\begin{tabular}{|c|c|c|c|c|}
\hline $\begin{array}{l}\text { Autor, ano } \\
\text { e país }\end{array}$ & $\begin{array}{l}\text { Categoria } \\
\text { profissional }\end{array}$ & Objetivo & Métodos & Resultados \\
\hline $\begin{array}{l}\text { Can et al. }{ }^{40} \text {, } \\
2010 . \\
\text { Turquia }\end{array}$ & Policiais & $\begin{array}{l}\text { Relatar caso de FAF de alta } \\
\text { energia em face e pescoço, sem } \\
\text { óbito da vítima. A bala avançou } \\
\text { através dos espaços retrofaciais } \\
\text { seguindo um curso não linear } \\
\text { e ficou retida na região para- } \\
\text { faríngea oposta, sem ferir } \\
\text { qualquer estrutura vital. }\end{array}$ & Relato de caso clínico. & $\begin{array}{l}\text { Apesar de ter sido atingido por } \\
\text { um projétil de arma de fogo de } \\
\text { alta energia cinética, a resultante } \\
\text { do dano foi uma “lesão de baixa } \\
\text { velocidade". O projétil manteve } \\
\text { energia para penetrar e dissecar } \\
\text { os tecidos. A abordagem escolhida } \\
\text { para tratamento foi de preservação } \\
\text { sem abordagem cirúrgica, com } \\
\text { acompanhamento regular. }\end{array}$ \\
\hline $\begin{array}{l}\text { Shah et al. }{ }^{38}, \\
2011 . \\
\text { Afeganistão }\end{array}$ & $\begin{array}{l}\text { Militares } \\
\text { de forças } \\
\text { armadas, } \\
\text { policiais, } \\
\text { civis }\end{array}$ & $\begin{array}{l}\text { Analisar os registros de } \\
\text { prontuários de pacientes } \\
\text { internados em unidade de } \\
\text { terapia intensiva que receberam } \\
\text { assistência clínica e cirúrgica } \\
\text { durante a guerra do Afeganistão. }\end{array}$ & $\begin{array}{l}\text { Estudo quantitativo a partir } \\
\text { de banco de dados do Joint } \\
\text { Theatre Trauma Registry sobre } \\
\text { pacientes internados em } \\
\text { centro de terapia intensiva } \\
\text { no período } 1^{\circ} \text { de maio a } \\
15 \text { de outubro de } 2009 \\
(\mathrm{~N}=188) \text {. }\end{array}$ & $\begin{array}{l}\text { Entre os pacientes atendidos, } 36 \% \\
\text { eram militares multinacionais, } 16 \% \\
\text { policiais e militares afegãos e } 48 \% \\
\text { civis. Entre os pacientes atendidos, } \\
26 \% \text { foram em decorrência de FAF, } \\
\text { perdendo apenas para as ocorrências } \\
\text { de ferimentos por artefatos } \\
\text { explosivos. }\end{array}$ \\
\hline $\begin{array}{l}\text { Navarro } \\
\text { Suay et } \\
\text { al. }{ }^{39}, 2011 . \\
\text { Afeganistão }\end{array}$ & $\begin{array}{l}\text { Militares } \\
\text { de forças } \\
\text { armadas, } \\
\text { policiais, } \\
\text { civis }\end{array}$ & $\begin{array}{l}\text { Analisar os casos de traumatismo } \\
\text { por arma de fogo e explosivos } \\
\text { admitidos no CTI do Hospital } \\
\text { Militar Espanhol de campanha. } \\
\text { Verificar a localização anatômica } \\
\text { das lesões que produziram maior } \\
\text { morbidade. }\end{array}$ & $\begin{array}{l}\text { Estudo observacional, } \\
\text { descritivo, longitudinal e } \\
\text { retrospectivo entre os anos } \\
\text { de } 2005 \text { e } 2008(\mathrm{~N}=86) \text {. }\end{array}$ & $\begin{array}{l}\text { Foram } 86 \text { pacientes atendidos, entre } \\
\text { civis, militares e policiais, } 30 \text { com FAF } \\
\text { e } 56 \text { com ferimentos por dispositivos } \\
\text { explosivos. Desse total, } 42 \% \text { eram } \\
\text { militares e } 14 \% \text { policiais locais. }\end{array}$ \\
\hline $\begin{array}{l}\text { Mark et al. }{ }^{50}, \\
\text { 2012. EUA }\end{array}$ & Policiais & $\begin{array}{l}\text { Determinar se o pneumotórax } \\
\text { é uma causa de morte evitável } \\
\text { significativa entre os policiais } \\
\text { vítimas de FAF, assim como entre } \\
\text { os militares das forças armadas. }\end{array}$ & $\begin{array}{l}\text { Estudo quantitativo com } \\
\text { análise do banco de dados } \\
\text { do U.S. Federal Bureau of } \\
\text { Investigation entre policiais } \\
\text { mortos em serviço no período } \\
\text { de } 1998 \text { a } 2007(\mathrm{~N}=108) \text {. } \\
\end{array}$ & $\begin{array}{l}\text { Nenhum médico legista identificou } \\
\text { especificamente o pneumotórax } \\
\text { como causa direta da morte } \\
\text { de policiais vítimas de FAF. O } \\
\text { pneumotórax parece ser um evento } \\
\text { raro entre policiais. }\end{array}$ \\
\hline $\begin{array}{l}\text { Fisher et al. }^{3}, \\
\text { 2013. EUA }\end{array}$ & Policiais & $\begin{array}{l}\text { Determinar o que significa } \\
\text { obstrução de via aérea como causa } \\
\text { de possível morte evitável entre } \\
\text { policiais acometidos por FAF. }\end{array}$ & $\begin{array}{l}\text { Estudo quantitativo } \\
\text { retrospectivo a partir do } \\
\text { banco de dados do U.S. } \\
\text { Federal Bureau of Investigation } \\
\text { entre policiais mortos em } \\
\text { serviço no período de } 1998 \text { a } \\
2007(\mathrm{~N}=42) \text {. } \\
\end{array}$ & $\begin{array}{l}42 \text { policiais morreram em decorrência } \\
\text { de FAF. Segundo autópsia, três } \\
\text { policiais sucumbiram por trauma das } \\
\text { vias aéreas. A intubação endotraqueal } \\
\text { foi a técnica de manejo de via aérea } \\
\text { artificial mais comum utilizada na } \\
\text { tentativa de ressuscitação. }\end{array}$ \\
\hline $\begin{array}{l}\text { Nagasako } \\
\text { et al. } .^{45} \text {, } \\
\text { 2013. Brasil }\end{array}$ & Policiais & $\begin{array}{l}\text { Relatar caso de policial de } 39 \text { anos } \\
\text { vítima de FAF no tórax. Projétil } \\
\text { alojado na parte superior do } \\
\text { mediastino, causando desvio do } \\
\text { esôfago sem extravasamento. } \\
\end{array}$ & Relato de caso clínico. & $\begin{array}{l}\text { Endoscopia mostrou um pequeno } \\
\text { orifício fistuloso. Após } 27 \text { dias do } \\
\text { trauma, o projétil foi removido com } \\
\text { sucesso. }\end{array}$ \\
\hline $\begin{array}{l}\text { Swedler } \\
\text { et al. }{ }^{8}, 2014 . \\
\text { EUA }\end{array}$ & Policiais & $\begin{array}{l}\text { Entender as circunstâncias } \\
\text { envolvidas nos homicídios de } \\
\text { policiais, a partir da análise das } \\
\text { narrativas dos relatórios do } \\
\text { Federal Bureau of Investigation, } \\
\text { Law Enforcement Officers Killed and } \\
\text { Assaulted. }\end{array}$ & $\begin{array}{l}\text { Análise das narrativas a partir } \\
\text { dos relatórios do Federal } \\
\text { Bureau of Investigation, Law } \\
\text { Enforcement Officers Killed and } \\
\text { Assaulted no período de } 1996 \\
\text { a } 2010(\mathrm{~N}=796) .\end{array}$ & $\begin{array}{l}796 \text { oficiais mortos em serviço, sendo } \\
67 \% \text { por armas de fogo de cano curto; } \\
10 \% \text { foram mortos com sua própria } \\
\text { arma de serviço. A circunstância de } \\
\text { maior risco foi durante a resposta a } \\
\text { chamadas de perturbação à ordem. }\end{array}$ \\
\hline $\begin{array}{l}\text { Blair et al. }{ }^{5} \\
\text { 2016. EUA }\end{array}$ & Policiais & $\begin{array}{l}\text { Descrever as características dos } \\
\text { homicídios ocorridos entre os } \\
\text { profissionais de segurança pública }\end{array}$ & $\begin{array}{l}\text { Estudo quantitativo e } \\
\text { qualitativo a partir da análise } \\
\text { do banco de dados National } \\
\text { Violent Death Reporting } \\
\text { System, no período de 2003- } \\
2013 \text { ( } \mathrm{N}=128) .\end{array}$ & $\begin{array}{l}\text { Ocorreram } 128 \text { homicídios } \\
\text { ocupacionais entre os profissionais } \\
\text { de segurança pública em } 17 \text { estados } \\
\text { do país, sendo } 91,4 \% \text { deles por FAF. } \\
\text { Os profissionais de segurança pública } \\
\text { têm maior risco de morrer de forma } \\
\text { violenta. }\end{array}$ \\
\hline
\end{tabular}


O documento mais antigo localizado é do ano de $1976^{51}$, o único publicado na década de 1970. Nas décadas de 1980 e 1990 foram identificados 4 artigos em cada uma. No século XXI, porém, houve grande crescimento de publicações, sobretudo devido aos conflitos no Oriente Médio, entre 2000 e $2009^{30,31,33-35,37}$. O período mais recente avaliado, entre 2010 e 2016, embora contemple apenas 7 anos, apresentou 8 artigos $^{3,5,8,38-40,45,50}$, o mesmo número de publicações das décadas de 1980 e 1990 somadas, reforçando a tendência de aumento de estudos voltados ao tema neste início de século, apesar de se considerar que o campo de pesquisa ainda seja pouco explorado.

Os artigos selecionados foram, em sua maioria, publicados em inglês (28), sendo os demais em espanhol (1), italiano (1) e alemão (1). A maioria é da área da saúde, exceto 2: um do direito forense e outro proveniente de revista militar. Dentre aqueles da saúde, têm-se: 17 em revistas relacionadas a especialidades médicas como a traumatologia e emergências médicas, 3 de medicina forense, 2 de psicologia, 3 de medicina militar e 4 de saúde pública.

Somente em 10 artigos foi possível identificar a idade dos profissionais de segurança pública e militares das forças armadas acometidos por armas de fogo: 9 eram sobre policiais e registraram idades que variaram entre 20 a 41 anos $^{9,40-47}$ e 1 sobre militares de forças armadas, que apresentou média de 24 anos de idade (desvio padrão de 5,9) para vítimas de perfurações por arma de fogo em cabeça, pescoço e face ${ }^{37}$.

Existe uma forte prevalência do sexo masculino entre os profissionais de segurança e militares das forças armadas ${ }^{43}$, variando de $95 \%$ em Plani, Bowley e Goosen ${ }^{46}$ a $96 \%$ no estudo de Navarro Suay et al. ${ }^{39}$. Quanto às circunstâncias envolvidas nas ocorrências de morbimortalidade por armas de fogo, os estudos apontam como causa predominante os ferimentos no exercício da profissão, como "mortos ou feridos em serviço" 3,5,7,8,31,46,48-50, embora essa informação não estivesse disponível em relatos de casos clínicos que apenas descreveram a fisiopatologia dos ferimentos e seus respectivos tratamentos, sem enfoque nas circunstâncias envolvidas ${ }^{40,42,44,45,47,51}$. As situações consideradas de maior risco para os policiais foram: confrontos com criminosos ${ }^{46}$, realização de prisão ou tentativa de prisão ${ }^{48}$ e resposta a chamadas de perturbação à ordem ${ }^{7,8,52}$. Já as mortes por armas de fogo entre militares das forças armadas foram classificadas por Kelly et al. ${ }^{35}$ e Champion et al. ${ }^{31}$ como "mortos em ação", e por Bird et al. ${ }^{30}$ e Hodgetts et al. ${ }^{34}$ como "mortes hostis", ambos fazendo referência a ocorrências das injúrias em combate. As circunstâncias consideradas de maior risco entre militares das forças armadas ficaram concentradas nas ações do grupamento de infantaria (cerca de $90 \%$ de todos os feridos em combate) ${ }^{31,32}$.
Outros fatores considerados importantes no aumento do risco entre os policiais foram: Plani, Bowley e Goosen ${ }^{46}$ mostraram maior concentração dos FAF entre os sargentos; Lester ${ }^{54,55}$ indicou maiores taxas de assassinados em cidades onde existe maior proporção de suicídios, homicídios, roubos e assaltos envolvendo arma de fogo, sugerindo que o aumento do uso deste tipo de armamento por criminosos pode configurar a maior causa provável de violência contra o policial; Kyriacou et al ${ }^{49}$ associaram o aumento do risco a fatores socioeconômicos, culturais e ocupacionais; Armour ${ }^{9}$ e Clerici et al. ${ }^{41}$ associaram os suicídios por armas de fogo ao estresse psicológico e à relativa facilidade de acesso às armas.

Alguns autores apontaram que os FAF entre militares das forças armadas em situação de guerra representaram o segundo mecanismo de ferimentos mais frequente, perdendo apenas para os dispositivos explosivos ${ }^{31-35,37-39}$, que apresentaram cerca do dobro da porcentagem dos casos de FAF, mantendo-se entre $23 \%$ e $37 \%^{30,31,33,34,36,39,51}$. Já entre os policiais, as fatalidades e ferimentos em serviço por arma de fogo representaram o principal mecanismo de injúria ${ }^{5,7,8,46,48,49}$, com exceção da polícia de Londres, que teve nos acidentes automobilísticos o principal evento causador de ferimentos ocupacionais ${ }^{49}$.

Quanto à localização dos ferimentos, 8 artigos não trouxeram a informação ou inviabilizaram a análise por não apresentarem resultados separando profissionais de segurança, militares das forças armadas e civis ${ }^{35,40,41,45,55}$ e/ou por não identificarem especificamente a arma de fogo como mecanismo produtor do ferimento, incluindo no mesmo grupo também os ferimentos produzidos por explosivos e instrumentos cortantes ${ }^{5,8,36}$. Entre os artigos que localizaram anatomicamente os FAF, 6 apresentaram relatos de casos clínicos descrevendo eventos únicos em regiões específicas do corpo, a saber: 2 em cabeça e pescoço ${ }^{42,49}, 1$ na região inguinal ${ }^{44}, 1$ no joelho ${ }^{46}$, 1 no tórax ${ }^{47}$ e 1 no abdome ${ }^{53}$; 3 referiram-se a FAF autoinfligidos ${ }^{9,43,49}$. Em apenas 3 estudos foram realizados levantamentos sobre a ocorrência de ferimentos entre os profissionais de segurança, informando as áreas anatômicas afetadas ${ }^{34,48,50}$.

Como pode ser visto na Tabela 1, apenas 3 artigos descreveram as áreas anatômicas acometidas por FAF, permitindo visualizar as regiões mais acometidas $^{32,46,48}$. Berman e Salter ${ }^{48}$ indicaram que os membros superiores e inferiores foram as regiões mais acometidas por ferimentos não fatais, seguidos pela cabeça-pescoço-face, abdome e tórax. Já entre os fatais, destacam-se tórax, cabeça-pescoço-face, membros superiores e inferiores e tórax. Plani, Bowley e Goosen $^{46}$ identificaram que as áreas mais atingidas foram membros superiores e inferiores, tórax, cabeça-pescoço-face e abdome; e Gofrit et al. ${ }^{32}$ apontaram 
que a região de cabeça-face-pescoço foi a mais atingida por ferimentos fatais, sendo a face a área com a maior concentração de ferimentos penetrantes, representando $28,7 \%$ do total. Nos casos de FAF autoinfligidos, a face foi a região mais atingida, especialmente nas áreas temporal e bucal ${ }^{9,41,47}$.

Tabela 1 Distribuição anatômica dos Ferimentos por Armas de Fogo (FAF)

\begin{tabular}{|c|c|c|c|c|}
\hline $\begin{array}{c}\text { Localização corporal } \\
\text { dos FAF }\end{array}$ & $\begin{array}{l}\text { Berman e Salter, } 1985^{48} \\
\text { FAF fatais entre Policiais }\end{array}$ & $\begin{array}{c}\text { Berman e Salter, } 1985^{48} \\
\text { FAF não fatais entre } \\
\text { Policiais }\end{array}$ & $\begin{array}{c}\text { Gofrit et al., } 1996^{32} \\
\text { FAF fatais entre Militares } \\
\text { das Forças Armadas }\end{array}$ & $\begin{array}{c}\text { Plani, Bowley e Goosen, } \\
2003^{46} \\
\text { FAF entre Policiais } \\
\end{array}$ \\
\hline $\begin{array}{l}\text { Membros superiores/ } \\
\text { inferiores }\end{array}$ & $6,9 \%$ & $51,6 \%$ & $16,5 \%$ & $46,0 \%$ \\
\hline $\begin{array}{l}\text { Cabeça-pescoço-coluna- } \\
\text { face }\end{array}$ & $44,8 \%$ & $20,2 \%$ & $44,4 \%$ & $33,5 \%$ \\
\hline Nádegas & $20,7 \%$ & $6,9 \%$ & & $12,5 \%$ \\
\hline Tórax & 27,6 & $10,1 \%$ & $39,1 \% *$ & $40,0 \%$ \\
\hline Abdome & - & $11,2 \%$ & & $30,0 \%$ \\
\hline
\end{tabular}

Quanto aos desdobramentos no desempenho profissional, apenas Plani, Bowley e Goosen ${ }^{46}$ trouxeram considerações, ainda que de forma superficial: $58 \%$ dos policiais retornaram ao trabalho como aptos, 21\% foram considerados aptos para serviços leves e com restrições e $21 \%$ foram afastados. Segundo os autores, policiais que sofreram FAF em serviço podem expressar ansiedade em retornar ao trabalho ou até mesmo não se tornarem aptos para o retorno em virtude de distúrbios psicológicos, o que corrobora achados de outros autores, que ressaltam a realidade estressante com a qual o policial convive diariamente em sua rotina profissional ${ }^{1,4,11-13,16,35,57}$.

Podemos verificar, entre os artigos selecionados, que as armas de fogo constituem um dos principais mecanismos de ferimento em serviço entre policiais, especialmente os do sexo masculino na faixa dos 30 anos. As morbimortalidades encontradas entre policiais ou militares de forças armadas podem ser considerados acidentes de trabalho quando acontecem durante o serviço ou em combate.

Em virtude de serem poucos os estudos ${ }^{32,46,48}$ que informaram as partes do corpo mais atingidas em FAF, não pudemos aprofundar a análise das circunstâncias em que o fenômeno acontece. Cabe ressaltar que muitas dessas lesões podem ser prevenidas a partir do uso de equipamentos de proteção individual apropriado, como o colete à prova de balas e o capacete balístico, o que deve ser uma medida de proteção adicional importante a ser considerada não apenas entre os militares das forças armadas em situação de guerra, como também entre profissionais de segurança pública em áreas urbanas.

As circunstâncias de maior risco para a ocorrência de FAF identificadas nos artigos selecionados são as ações de prisão, tentativa de prisão em confrontos contra criminosos e em ação de resposta a chamado policial para verificação de perturbação à ordem. Tais circunstâncias demandam maior investimento em treinamento tático a fim de que sejam adotados métodos e meios, no emprego da ação policial, que aumentem a segurança operacional desses profissionais.

A arma de fogo também é o principal mecanismo para produção de ferimentos autoprovocados entre os profissionais de segurança pública. Segundo os artigos selecionados, isso se relaciona ao fato de possuírem acesso facilitado a esse tipo de dispositivo. A violência autoprovocada é um grave indício de intenso sofrimento psíquico vivenciado por essa classe trabalhadora, o que demanda cuidados adicionais direcionados à saúde mental/emocional.

A despeito da alta representatividade da ocorrência de mortalidade e morbidade por FAF entre os profissionais de segurança e militares das forças armadas, existem poucos estudos que discutem as repercussões físicas das injúrias para o trabalho desses profissionais $5,7,8,46,48,49,53$. As características dos ferimentos em serviço ou em combate diferem daquelas encontradas na prática civil, tanto do ponto de vista epidemiológico quanto nas alternativas para o seu tratamento ${ }^{31}$. Sendo o FAF o principal mecanismo de injúria durante o trabalho dos policiais, este tipo de agravo, no Brasil configurado como acidente de trabalho, que gera mortes e incapacidades significativas em um segmento profissional, consiste em um problema de saúde pública que precisa ser pesquisado. Apesar disso, nesta revisão integrativa, nenhum artigo com informações sobre vitimização produzida por FAF entre profissionais de segurança brasileiros foi encontrado.

No Brasil, não há um sistema nacional integrado que registre a morbimortalidade dos agentes de segurança pública. Também não é possível identificar e 
produzir relatórios sobre esses agravos a partir dos Sistemas de Informação do Ministério da Saúde, tais como o Sistema de Informação de Agravos de Notificações (Sinan), o Sistema de Informação sobre Mortalidade (SIM), o Sistema de Informação Hospitalares do SUS (SIHSUS), o Viva Inquérito e o Sistema de Informação para a Gestão do Trabalho em Saúde (SGTES). Tal impedimento se dá pela falta de sistematização de dados que viabilizem a construção de indicadores de saúde para essa classe trabalhadora. Segundo a Rede Interagencial de Informação para Saúde (Ripsa), cujo objetivo é aperfeiçoar a produção de informação em saúde instruindo sobre os critérios técnicos recomendados para a construção de indicadores, tal limitação está relacionada ao regime próprio de previdência social desta categoria. As informações colhidas nos seus sistemas advêm de bancos de dados de trabalhadores vinculados ao Regime Geral de Previdência Social ou dos hospitais vinculados ao SUS ${ }^{56}$. Além dos limites técnicos, há, historicamente, falta de atenção à saúde dos profissionais de segurança pública ${ }^{24}$.

Com isso, não é possível saber a real dimensão da frequência desse tipo de trauma entre profissionais de segurança pública e militares das forças armadas no país; as intervenções em saúde necessárias para seu tratamento e seu custo; o tempo médio de afastamento do serviço até a reabilitação; as repercussões na vida e na saúde, tanto física quanto mental; as circunstâncias em que esse tipo de traumatismo acontece; a prevalência por sexo, idade, cor/raça e etnia e tempo de serviço; dentre outras informações que poderiam ajudar a caracterizar as vítimas de FAF e, então, possibilitar a elaboração de medidas para enfrentamento desta problemática, tanto preventivas quanto curativas.
A falta de atenção em saúde voltada para o policial enquanto trabalhador, no Brasil, tem distanciado esses profissionais da pauta da cidadania ${ }^{13}$. As consequências dessa forma de exercer a profissão têm resultado, na prática, em altas taxas de mortalidade policial no país, com risco de morte 3 vezes superior ao cidadão comum $^{58}$. Entre policiais do Rio de Janeiro, esse risco chega a ser 6,5 vezes maior, se comparado ao vivido pela população geral da cidade ${ }^{13}$.

A limitação de informações poderia ser minimizada caso teses, dissertações e livros a respeito FAF fossem mais frequentes e a legislação específica fosse também estudada. A fragilidade metodológica de alguns artigos também dificulta análises comparativas mais aprofundadas. Não foi realizada a avaliação do risco de viés dos estudos individuais, o que é uma limitação desta revisão.

\section{Considerações finais}

Ao constatar poucos estudos que discutem as repercussões físicas para o trabalho entre os profissionais que sofrem FAF e a ausência de preocupação com o tema no cenário nacional, esta revisão integrativa aponta para a existência de uma lacuna nas pesquisas em saúde que necessita ser preenchida a fim de identificar aspectos importantes, como: o perfil epidemiológico das vítimas; os fatores de risco e de proteção envolvidos nesse tipo de agravo; e os impactos dos traumatismos por arma de fogo e suas repercussões, tanto para o exercício de sua função como para a vida sociofamiliar desses profissionais. Com a obtenção de tais informações seria possível propor medidas de prevenção e promoção da saúde para essa classe trabalhadora.

\section{Contribuições de autoria}

Maia ABP foi responsável pelo desenho do projeto, revisão bibliográfica, coleta e interpretação dos dados, elaboração e revisão do manuscrito, aprovação da versão final publicada. Assis SG e Ribeiro FML foram responsáveis pela revisão do estudo e do manuscrito e aprovação da versão final publicada.

\section{Referências}

1. Minayo MSC, Souza ER. Missão investigar: entre o ideal e a realidade de ser policial. 2nd ed. Rio de Janeiro: Garamond; 2003.

2. Ferreira DKDS, Augusto LGDS, Silva JM. Condições de trabalho e percepção da saúde de policiais militares. Cad Saude Colet. 2008;16(3):403-20.

3. 3. Fisher LA, Callaway DW, Sztajnkrycer MD. Incidence of fatal airway obstruction in police officers feloniously killed in the line of duty: a 10year retrospective analysis. Prehosp Disaster Med. 2013;28(5):466-70.

4. Gershon RR, Lin S, Li X. Work stress in aging police officers. J Occup Environ Med. 2002;44(2):160-7.

5. Blair JM, Fowler KA, Betz CJ, Baumgardner JL. Occupational homicides of law enforcement 
officers, 2003-2013: data from the National Violent Death Reporting System. Am J Prev Med. 2016;51(5 Suppl 3):S188-96.

6. Violanti JM, Hartley TA, Gu JK, Fekedulegn D, Andrew ME, Burchfiel CM. Life expectancy in police officers: a comparison with the US general population. Int J Emerg Ment Health. 2013;15(4):217-28.

7. Clarke C, Zak MJ. Fatalities to law enforcement officers and firefighters, 1992-1997. Compensation and Working Conditions. 1999 Summer:3-7.

8. Swedler DI, Kercher C, Simmons MM, Pollack KM. Occupational homicide of law enforcement officers in the US, 1996-2010. Inj Prev. 2013;20(10):35-40.

9. Armour A. A study of gunshot suicides in Northern Ireland from 1989 to 1993. Sci Justice. 1996;36(1):21-5.

10. Kelley TM. Mental health and prospective police professionals. Policing. 2005;28(1):6-29.

11. Minayo MCS, Souza ER, Constantino P. Missão prevenir e proteger: condições de vida, trabalho e saúde dos policiais militares do Rio de Janeiro. Rio de Janeiro: Editora Fiocruz; 2008.

12. Souza ER, Franco LG, Meireles CC, Ferreira VT, Santos NC. Sofrimento psíquico entre policiais civis: uma análise sob a ótica de gênero. Cad Saude Publica. 2007;23(1):105-14.

13. Minayo MSC, Souza ER, Constantino P. Riscos percebidos e vitimização de policiais civis e militares na (in)segurança pública. Cad Saude Publica. 2007;23(11):2767-79.

14. Brasil. Constituição (1988). Constituição da República Federativa do Brasil. Brasília, DF: Senado Federal; 2017.

15. Waiselfisz JJ. Mapa da violência 2013: mortes matadas por armas de fogo. Rio de Janeiro: Flacso; 2013.

16. Waiselfisz JJ. Mapa da violência 2016: homicídios de armas de fogo no Brasil. Rio de Janeiro: Flacso; 2016.

17. Viva: vigilância de violências e acidentes: 2013 e 2014. Brasília, DF; 2017.

18. Souza ER, Njaine K, Minayo MCS. Qualidade da informação sobre violência: um caminho para a construção da cidadania. Cadernos do Programa de Pós-graduação em Ciência da Informação. 1996;2:104-12.

19. Fórum Brasileiro de Segurança Pública. Anuário Brasileiro de Segurança Pública [Internet]. 2016 [citado em 4 ago 2017]. Disponível em: http://www. forumseguranca.org.br/storage/10_anuario_site_1811-2016-retificado.pdf

20. Número de PMs mortos no Rio cai pela metade em 2019. Extra [Internet]. 2019 Apr 2 [citado em 8 jul 2019]. Disponível em: https://extra.globo.com/ casos-de-policia/numero-de-pms-mortos-no-rio-caipela-metade-em-2019-23566691.html

21. Vale LD. Relatório vitimização policial: 1998 a novembro de 2015 [Internet]. Rio de Janeiro: Instituto de Segurança Pública do Rio de Janeiro;
2015 [citado em 4 ago 2017]. Disponível em: http:// arquivos.proderj.rj.gov.br/isp_imagens/uploads/ RelatorioVitimizacao2015.pdf

22. Anchieta VC, Galinkin AL, Mendes AMB, Neiva ER. Trabalho e riscos de adoecimento: um estudo entre policiais civis. Psic, Teor e Pesq. 2011;27(2):199-208.

23. Muniz J, Soares BM, editors. Mapeamento da vitimização de policiais no Rio de Janeiro. Rio de Janeiro: Centro de Estudos de Segurança e Cidadania; 1998.

24. Souza ER, Minayo MCS. Policial, risco como profissão: morbimortalidade vinculada ao trabalho. Cien Saude Colet. 2005;10(4):917-28.

25. Minayo MCS, Assis SG, Oliveira RVC. Impacto das atividades profissionais na saúde física e mental dos policiais civis e militares do Rio de Janeiro. Cien Saude Colet. 2011;16(4):2199-209.

26. Calabrez MCT. Traumatologia forense. In: Silva M, Cavielli ITP, editors. Compêndio de odontologia legal. São Paulo: Medsi; 1997. p. 245-88.

27. Barros PL. Balística forense [trabalho de conclusão de curso]. Goiânia: Universidade Católica de Goiás; 2001.

28. Segundo AVL, Zimmermman RD, Nogueira EFDC, Lopes PHDS. Inclusão do estudo da balística no tratamento dos ferimentos faciais por projétil de arma de fogo. Rev Cir Traum Buco-maxilo-facial. 2013;13(4):65-70.

29. Mendes KDS, Silveira RCCP, Galvão CM. Revisão integrativa: método de pesquisa para a incorporação de evidências na saúde e na enfermagem. Texto \& Contexto Enferm. 2008;17(4):758-64.

30. Bird SM, Fairweather CB. Military fatality rates (by cause) in Afghanistan and Iraq: a measure of hostilities. Int J Epidemiol. 2007;36(4):841-6.

31. Champion HR, Bellamy RF, Roberts CP, Leppaniemi A. A profile of combat injury. J Trauma. 2003;54(5 Suppl):13-9.

32. Gofrit ON, Kovalski N, Leibovici D, Shemer J, O'hana A, Shapira SC. Accurate anatomical location of war injuries: analysis of the Lebanon war fatal casualties and the proposition of new principles for the design of military personal armour system. Injury. 1996;27(8):577-81.

33. Hinsley DE, Rosell PAE, Rowlands TK, Clasper JC. Penetrating missile injuries during asymmetric warfare in the 2003 Gulf conflict. Br J Surg. 2005;92(5):637-42.

34. Hodgetts TJ, Davies S, Midwinter M, Russell R, Smith J, Clasper J, Moorhouse I. Operational mortality of UK service personnel in Iraq and Afghanistan: a one year analysis 2006-7. J R Army Med Corps. 2007;153(4):252-4.

35. Kelly JF, Ritenour AE, McLaughlin DF, Bagg KA, Apodaca AN, Mallak CT, et al. Injury severity and causes of death from Operation Iraqi Freedom and Operation Enduring Freedom: 2003-2004 versus 2006. J Trauma. 2008;64(2 Suppl):S21-6. 
36. Stansfield T, Rushforth G. UK Armed Forces unintentional firearm injuries. J R Army Med Corps. 2009;155(1):20-3.

37. Wade AL, Dye JL, Mohrle CR, Galarneau MR. Head, face, and neck injuries during Operation Iraqi Freedom II: results from the US NavyMarine Corps Combat Trauma Registry. J Trauma. 2007;63(4):836-40.

38. Shah K, Pirie MS, Compton ML, McAlister MV, Church MB, Kao CNR. Utilization profile of the trauma intensive care unit at the Role 3 Multinational Medical Unit at Kandahar Airfield between May 1 and Oct. 15, 2009. Can J Surg. 2011;54(6):130.

39. Navarro Suay R, Bartolomé Cela E, Jara Zozaya I, Hernández Abadía de Barbará A, Gutiérrez Ortega C, García Labajo JG, et al. G. Even more critical medicine: a retrospective analysis of casualties admitted to the intensive care unit in the Spanish Military Hospital in Herat (Afghanistan). Med Intensiva. 2011;35(3):157-65.

40. Can M, Yildirim N, Ataç GK. Dissecting firearm injury to the head and neck with non-linear bullet trajectory: a case report. Forensic Sci Int. 2010;197(1-3):e13-7.

41. Clerici CA, Invernizzi R, Veneroni L, De’Micheli A. Suicidi e omicidi con l'arma di ordinanza: analisi della casistica nelle guardie particolari giurate in Italia. G Ital Med Lav Erg. 2009;31(1):a10-5.

42. Ebbs SR. Policeman's groin: an unusual occupational injury. Injury. 1990;21(3):182-192.

43. Ehikhamenor EE, Ojo MA. Comparative analysis of traumatic deaths in Nigeria. Prehosp Disaster Med. 2005;20(3):197-201.

44. Gutiérrez V, Radice F. Late bullet migration into the knee joint. Arthroscopy. 2003;19(3):e15.

45. Nagasako CK, Montes CG, Lopes LR, Bossi M, Mesquita MA. Endoscopic removal of a bullet after mediastinum gunshot injury. Gastrointestinal Endosc. 2013;77(6):955-6.

46. Plani F, Bowley DM, Goosen J. Death and injury on duty: a study of South African police officers. S Afr Med J. 2003;93(11):851-3.
47. Rupp WR, Eusemann J, Faller-Marquardt M. Early postmortem scavenging by a dog after the suicide of a police officer by a gunshot to the head. Arch Kriminol. 2001;207(3):73-80.

48. Berman AT, Salter F. Low-velocity gunshot wounds in police officers. Clin Orthop Relat Res. 1985;192:113-9.

49. Kyriacou DN, Monkkonen EH, Peek-Asa C, Lucke RE, Labbett S, Pearlman KS, et al. Police deaths in New York and London during the twentieth century. Inj Prev. 2006;12(4):219-24.

50. Mark AC, Wimberger N, Sztajnkrycer MD. Incidence of tension pneumothorax in police officers feloniously killed in the line of duty: a tenyear retrospective analysis. Prehosp Disaster Med. 2012;27(1):94-7.

51. Wilson JTH. Penetrating trauma of colon, cava, and cord. J Trauma. 1976;16(5):411-3.

52. National Institute for Occupational Safety and Health. Line-of-duty death report: Career lieutenant killed and firefighter injured by gunfire while responding to call in Kentucky. Fire Rescue Mag. 2006;24(6):36.

53. Raghib SYA. Firearm fatalities in Jordan. Med Sci Law. 1984;24(3):213-21.

54. Lester D. Police officers killed and the guns used by criminals. Psychol Rep. 1982;50(3 Pt 2):1206.

55. Lester D. The police as victims: the role of guns in the murder of police. Psychol Rep. 1987;60(2):366.

56. Rede Interagencial de Informação para a Saúde. Indicadores básicos para a saúde no Brasil: conceitos e aplicações. 2nd ed. Brasília, DF: Organização Pan-Ámericana da Saúde; 2008.

57. Cooper CL, Cartwright S. Organizational management of stress and destructive emotions at work. In: Payne RL, Cooper CL, editors. Emotions at work: theory, research and applications for management. Chichester: John Wiley \& Sons; 2001. p. 269-80.

58. Bueno S, Cerqueira DL, Lima RS. Sob fogo cruzado II: letalidade da ação policial. Anuário Brasileiro de Segurança Pública. 2013;7:118-27. 